BMJ Open

Ophthalmology

\title{
A systematic review of clinical practice guidelines for childhood glaucoma
}

\author{
Gareth Lingham (i) , ,,2 Sahil Thakur, ${ }^{3}$ Sare Safi, ${ }^{4,5}$ Iris Gordon, ${ }^{6}$ \\ Jennifer R Evans (1D, , ${ }^{6}$ Stuart Keel (i) ${ }^{7}$
}

To cite: Lingham G,

Thakur S, Safi S, et al. A systematic review of clinical practice guidelines for childhood glaucoma. BMJ Open Ophthalmology 2022;7:e000933. doi:10.1136/ bmjophth-2021-000933

\section{- Additional supplemental} material is published online only. To view, please visit the journal online (http://dx.doi. org/10.1136/bmjophth-2021000933).

GL and ST are joint first authors.

Received 1 November 2021 Accepted 18 January 2022

\section{Check for updates}

\section{(C) Author(s) (or their} employer(s)) 2022. Re-use permitted under CC BY-NC. No commercial re-use. See rights and permissions. Published by BMJ.

For numbered affiliations see end of article.

\section{Correspondence to} Dr Gareth Lingham; gareth. lingham@tudublin.ie

\section{ABSTRACT}

Objective To conduct a systematic review to identify and critically appraise clinical practice guidelines on the assessment, diagnosis and management of childhood glaucoma.

Methods and analysis A systematic literature search of databases and professional websites for clinical practice guidelines published on eye conditions between 2010 and April 2020 in English was conducted. Identified guidelines were screened for relevance to childhood glaucoma and exclusion criteria applied. Guidelines that passed the screening and quality appraisal with the Appraisal of Guidelines for Research and Evaluation II (AGREE II) tool and, if they achieved a mean score of $\geq 45$ and $\geq 3$ on subsets of 9 and 5 AGREE II items, respectively, were selected for inclusion and data extracted using a standardised form.

Results Following screening and critical appraisal, three guidelines were included for data extraction. None of the three guidelines was specifically developed for childhood glaucoma. A consistent recommendation was that children should undergo some form of eye screening examination or a comprehensive eye assessment to detect paediatric eye disease. Children at high risk of childhood glaucoma should undergo additional screening. One clinical practice guideline recommended interventions for childhood glaucoma consisting of tube surgery and topical betablockers or carbonic anhydrase inhibitors. Recommended interventions for childhood glaucoma were based on lowquality to moderate-quality evidence or expert opinion. Conclusion Based on our selection criteria, we did not identify any high-quality clinical practice guidelines specifically targeted at childhood glaucoma. This is compounded by the lack of high-quality evidence on childhood glaucoma.

\section{INTRODUCTION}

Childhood glaucoma is a rare eye condition with estimated incidence of 2.29 per 100000 people below 20 years of age in the USA to 5.41 per 100000 live births in the $\mathrm{UK}^{12} \mathrm{~A}$ higher incidence has been reported in Asian populations. ${ }^{13-5}$ Childhood glaucoma is an important cause of vision loss and is estimated to be responsible for $10 \%$ and $3 \%$ of childhood blindness in African regions and the USA, respectively. ${ }^{6}$ Childhood glaucoma is not a single disease entity and may arise secondary to one or more underlying

\section{Key messages}

What is already known about this subject?

- Childhood glaucoma is a rare, but devastating, eye condition among children, which requires often lifelong management and treatment.

\section{What are the new findings?}

Clinical practice guidelines specifically targeting childhood glaucoma are scarce.

- This systematic review identified only three guidelines, none of which was specific to childhood glaucoma.

How might these results change the focus of research or clinical practice?

This systematic review will inform a Package of Eye Care Interventions developed by WHO.

- There is need for a high-quality clinical practice guideline for childhood glaucoma.

congenital anatomical defects, genetic alterations, neoplastic, infectious, inflammatory or postsurgical causes. The Childhood Glaucoma Research Network defines childhood glaucoma as intraocular pressure (IOP)related ocular damage and classifies it into primary and secondary types. ${ }^{7}$ Primary childhood glaucoma includes primary congenital glaucoma (PCG) and juvenile open angle glaucoma. Secondary childhood glaucoma includes glaucoma associated with nonacquired ocular anomalies (eg, Axenfeld Rieger anomaly), non-acquired systemic diseases (eg, Down syndrome), acquired conditions (eg, uveitis) and previous cataract surgery. ${ }^{7}$

Despite several available options for management of childhood glaucoma, the prognosis is often suboptimal. People with childhood glaucoma have a reduced quality of life ${ }^{8}$ and visual acuity is often poor with approximately $25 \%$ of children with PCG meeting the WHO's definition of blindness in one Indian cohort. ${ }^{9}{ }^{10}$ As the disease and its management essentially requires lifelong monitoring, there is also a significant impact on the caregiver quality of life, indicating that 
evidence-based interventions are required at a multitude of levels to optimise patient outcomes. ${ }^{11}$

Childhood glaucoma has been identified as a priority eye condition for inclusion in the WHO's Package of Eye Care Interventions (PECI). The PECI is being developed in response to a recommendation from the World Report on Vision to imbed eye care into Universal Healthcare Coverage. The PECI will be an evidence-based tool that aims to improve access to, and the provision of, eye care by assisting Member States, particularly low-income and middle-income nations, with the planning, budgeting and integration of eye care interventions. ${ }^{12}$ For example, in the context of childhood glaucoma, the PECI will provide recommendations on cost-effective, evidencebased interventions and the resources required to implement these interventions. Stage 2 of the PECI is a systematic review of clinical practice guidelines (CPGs) to identify recommended, evidence-based interventions for priority eye conditions. Later stages of the PECI development include the review and selection of recommended interventions for inclusion in the PECI by a panel of experts from low-resource, middle-resource and highresource settings, identification of required resources and peer review of the package. ${ }^{12}$

This systematic literature review aims to identify CPGs for childhood glaucoma and extract data to support the development of the WHO PECI.

\section{METHODS}

This systematic review of CPGs was conducted in compliance with the methodology outlined in the introductory PECI paper. ${ }^{12}$ A CPG was defined according to the Institute of Medicine definition: 'statements that include recommendations, intended to optimise patient care that are informed by a systematic review of evidence and an assessment of the benefits and harms of alternative care options' ${ }^{13}$ Exclusion criteria for each stage of screening are provided in table 1 .

\section{Systematic literature search}

A systematic literature search for CPGs was conducted on 9 March 2020 in the following academic databases:

\begin{tabular}{|c|c|}
\hline & Reason for exclusion \\
\hline $\begin{array}{l}\text { Title and } \\
\text { abstract } \\
\text { screening }\end{array}$ & $\begin{array}{l}\text { The identified literature was not a CPG. } \\
\text { The guideline was not published in the last } 10 \text { years. } \\
\text { The guideline was not in English. } \\
\text { The guideline was not developed for selected eye } \\
\text { conditions. }\end{array}$ \\
\hline $\begin{array}{l}\text { Full-text } \\
\text { screening }\end{array}$ & $\begin{array}{l}\text { There was commercial funding or unmanaged } \\
\text { conflicts of interest present. } \\
\text { Absence of affiliation of authors. }\end{array}$ \\
\hline $\begin{array}{l}\text { Quality } \\
\text { appraisal }\end{array}$ & $\begin{array}{l}\text { The average score of the two researchers for items } \\
4,7,8,12 \text { or } 22 \text { is below } 3 \text {. } \\
\text { The sum of the average score of the two } \\
\text { researchers for all nine items is }<45 \text {. }\end{array}$ \\
\hline
\end{tabular}

CPG, clinical practice guideline.
MEDLINE, Embase, CINAHL and Global Index Medicus. In addition, a search of guideline databases and the websites of several optometry and ophthalmology associations were also undertaken for CPGs that met the inclusion criteria. The search terms and filters were adapted according to the search options in the specific guideline databases and websites. Guidelines were limited to publication in the last 10 years and published in English. The full search strategy and list of databases and websites searched are presented in online supplemental appendix 1 .

\section{Title and abstract screening}

Title and abstracts of the records identified in the searches were screened independently by two authors (GL, SS) using the semi-automated AbstrackR software. ${ }^{14}$ The following exclusion criteria were applied: the document was not a CPG, the guideline was not published in the last 10 years, the guideline was not in English or the guideline was not developed for a priority eye condition for PECI. Discrepancies were resolved by a representative from WHO (SK) and Cochrane Eyes and Vision (CEV; JRE).

\section{Full-text screening}

CPGs identified as potentially relevant to childhood glaucoma based on title and abstract screening underwent independent full-text screening by two authors (GL, ST). Broadly, guideline relevant to paediatric populations, glaucoma or some combination of the two were selected for full-text screening and we opted to be inclusive to avoid missing eligible guidelines. CPGs were excluded if they were deemed not relevant to childhood glaucoma, did not list the affiliations of all authors, did not declare potential conflicts of interest or there were significant conflicts of interest present. Potentially significant conflicts of interest included scenarios such as a large proportion of authors having relevant conflicts of interest, the first or senior author having a direct, proprietary conflict of interest or a lack of a description for managing relevant conflicts of interest, when present. Where it was unclear whether there was a significant conflict of interest, the full-text screening team was encouraged to consult with a third (SK) and fourth author (JRE) from WHO and CEV, respectively. Other discrepancies were resolved through discussion between the two authors (GL and ST) or, in the event a consensus could not be reached, by discussion with the aforementioned third and fourth authors (SK and JRE).

\section{Quality appraisal}

The selected CPGs underwent independent quality appraisal by two authors (GL, ST) using the Appraisal of Guidelines for Research and Evaluation II (AGREE II) tool. ${ }^{15}$ The AGREE II tool contains 23 items relating to 6 quality domains: scope and purpose, stakeholder involvement, rigour of development, clarity of presentation, applicability and editorial independence. Based 
Table 2 Details and AGREE II ratings of clinical practice guidelines that met eligibility criteria

\begin{tabular}{|c|c|c|c|c|c|c|c|c|c|c|c|c|c|}
\hline \multirow[b]{2}{*}{ Organisation } & \multirow[b]{2}{*}{ Region } & \multirow[b]{2}{*}{ Included } & \multirow[b]{2}{*}{ Publication year } & \multicolumn{10}{|c|}{ AGREE II ratings of each reviewer separately } \\
\hline & & & & 4 & 7 & 8 & 10 & 12 & 13 & 15 & 22 & 23 & Total \\
\hline $\mathrm{AAO}^{18}$ & USA & Yes & 2017 & 7 & 7 & 3 & 5 & 6 & 6 & 5 & 7 & 7 & 53 \\
\hline \multirow[t]{2}{*}{$\mathrm{AOA}^{19}$} & USA & Yes & 2017 & 7 & 4 & 7 & 6 & 7 & 7 & 6 & 7 & 4 & 55 \\
\hline & & & & 7 & 6 & 7 & 7 & 7 & 7 & 7 & 7 & 5 & 60 \\
\hline $\mathrm{NHMRC}^{17}$ & & & & 7 & 4 & 6 & 5 & 5 & 5 & 5 & 6 & 6 & 49 \\
\hline \multirow[t]{2}{*}{ Anwar et $a l^{26}$} & USA & No & 2013 & 4 & 1 & 1 & 2 & 5 & 4 & 4 & 2 & 6 & 29 \\
\hline & & & & 4 & 1 & 1 & 1 & 3 & 4 & 3 & 2 & 5 & 24 \\
\hline \multirow[t]{2}{*}{$\mathrm{EGS}^{27}$} & EU & No & 2014 & 7 & 2 & 2 & 4 & 5 & 3 & 5 & 4 & 4 & 3 \\
\hline & & & & 6 & 4 & 5 & 4 & 6 & 5 & 5 & 5 & 4 & 44 \\
\hline
\end{tabular}

Titles of the AGREE II items are as follows: 4-the guideline development groups include individuals from all relevant professional groups; 7-systematic methods were used to search for evidence; 8-the criteria for selecting the evidence are clearly described; $10-$ the methods for formulating the recommendations are clearly described; 12-there is an explicit link between the recommendations and the supporting evidence; 13 -the guidelines has been externally reviewed by experts prior to publication; 15 -the recommendations are specific and unambiguous; 22-the views of the funding body do not influence the content of the guideline; 23 -competing interests of guideline development group members have been recorded and addressed.

AAO, American Academy of Ophthalmology; AGREE II, Appraisal of Guidelines for Research and Evaluation II; AOA, American Optometric Association; AUS, Australia; EGS, European Glaucoma Society; EU, Europe; NHMRC, National Health and Medical Research Council; SE, Sweden; SOS, Swedish Ophthalmolgical Society.

on a consensus finding process prior to this review, ${ }^{16}$ we only used a subset of AGREE II items to appraise CPGs, specifically items 4, 7, 8, 10, 12, 13, 15, 22 and 23 (item names provided in table 2). These items are in the domains of stakeholder involvement, rigour of development, clarity of presentation and editorial independence and were recommended for use by the WHO Guideline Review Committee Secretariat, as they were deemed most relevant to the development of packages of care. To be eligible for inclusion, the average result for items 4,7 , 8,12 and 22 had to be $\geq 3$, and the average sum score of items $4,7,8,10,12,13,15,22$ and 23 had to be $>45$.

\section{Final guideline selection}

To facilitate timely development of the PECI, a maximum of five CPGs were able to be selected for data extraction. Where more than five CPGs were eligible, guidelines were to be selected according to the following criteria: quality, publication date and comprehensiveness (ie, applicability to different settings).

\section{Data extraction}

Data were extracted from the selected CPGs using a standardised form that recorded information on the recommendation (type of recommendation, dosage, target group, etc), the strength of recommendation and the quality of the evidence used to inform the recommendation by the guideline development group. Data were tabulated and organised according to intervention type: screening, assessment, prevention, promotion or treatment.
Recommended eye care interventions for childhood glaucoma were extracted from CPGs by one author (GL or ST) and independently checked by a second author (GL or ST). The process was repeated for all the guidelines until agreement on the recommended eye care interventions was reached.

\section{RESULTS}

\section{Screening, appraisal and selection of guidelines}

The results of the selection process are reported in figure 1. After the initial title and abstract screening, 68 reports were identified as potentially relevant to childhood glaucoma. On review of the full-text report, 29 of these guidelines were deemed not relevant to childhood glaucoma, 27 did not report either potential conflicts of interest or affiliations of authors, 1 had significant conflicts of interest among authors and 5 did not meet the criteria of a CPG on full-text review, leaving 6 CPGs for the AGREE II appraisal.

The results of the AGREE II appraisal are shown in table 2 . There was very good overall agreement between the two raters (one-way intraclass correlation $=0.83$ ). After the AGREE II appraisal, three of the six CPGs were excluded: one due to the average score of the two researchers for items $4,7,8,12$ or 22 being $<3$ and two CPGs were excluded due to the sum of the average score of the two researchers for all items being $<45$. Of the three CPGs that were excluded during the AGREE II appraisal, one was aimed at addressing the side effects of glaucoma therapy while the remaining two were CPGs aimed at all 

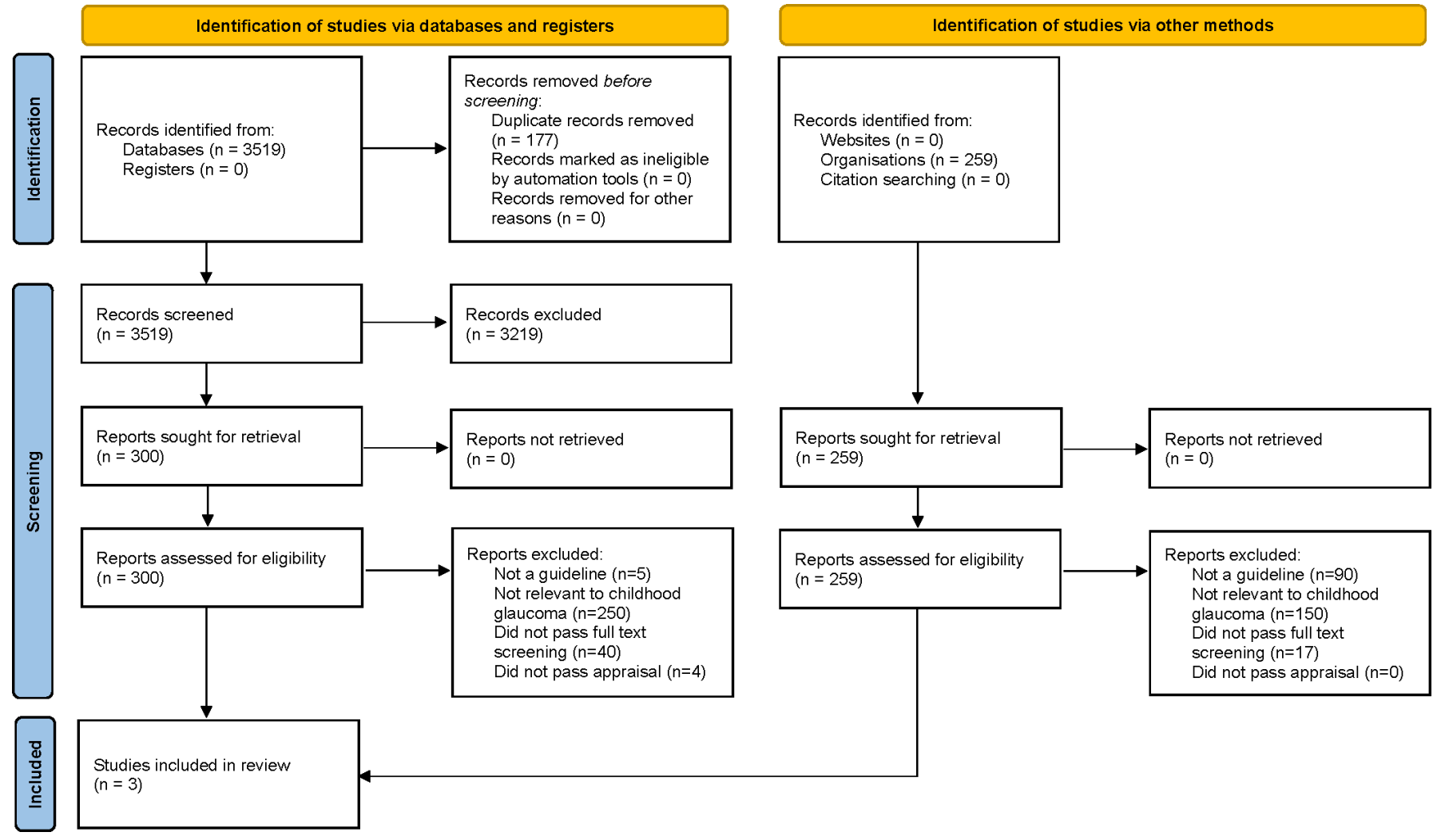

Figure 1 Preferred Reporting Items for Systematic Reviews and Meta-Analyses flow chart summarising the results of the literature review to identify clinical practice guidelines for childhood glaucoma.

types of glaucoma. These excluded guidelines performed most poorly in areas relating to reporting of systematic review methods and methods for formulating recommendations.

We ultimately selected three $\mathrm{CPGs}^{17-19}$ for the data extraction phase. The extracted recommendations are shown in table 3 . Two of the three included guidelines were published in the USA and related to the ocular assessment of children and infants and thus were not directly aimed at detection and management of childhood glaucoma. These two CPGs had the highest overall AGREE II scores. The remaining selected CPG was published in Australia in 2010 and was aimed at diagnosis and management of glaucoma at all ages and only a small part of the CPG was dedicated to childhood glaucoma. Therefore, we did not identify a CPG that specifically targeted childhood glaucoma.

\section{Guideline recommendations}

Of the recommendations extracted, strongly recommended interventions largely related to the assessment of infants and children to detect eye conditions such as childhood glaucoma, as well as the assessment of IOP in the diagnosis and management of glaucoma. Screening of first-degree relatives of those with glaucoma, including those with genetic syndromes that are highly associated with childhood glaucoma, was also strongly recommended.

Tube surgery was strongly recommended for long-term IOP control in patients at high risk of trabeculectomy failure (such as in childhood glaucoma) and in glaucoma following cataract surgery. Although not formally recommended, tube surgery was noted to be an appropriate first-line treatment for some secondary causes of childhood glaucoma. Topical beta-blockers and carbonic anhydrase inhibitors were recommended with intermediate strength for the management of childhood glaucoma, although these therapies should be used with caution due to the potential for adverse events and the quality of evidence was noted to be low. Surveillance of patients on long-term steroid medication including assessment of the optic nerve head, anterior chamber and visual field was recommended with weak or intermediate strength. These recommendations, however, were targeted at all individuals with glaucoma or at risk of glaucoma and were not specific to childhood glaucoma.

The quality of evidence used for formulating recommendations varied considerably. Recommendations relating to the screening or examination of children to detect paediatric eye disease or certain ocular assessments for the diagnosis of glaucoma were generally of moderatequality or good-quality evidence, with some exceptions. There was only low-quality evidence to support the use of topical IOP-lowering medication for the treatment of childhood glaucoma. Interestingly there was deemed to be moderate-quality evidence for the use of tube surgery; however, this recommendation was for the use of tube surgery where trabeculectomy is likely to fail including, but not limited to, some childhood glaucomas. ${ }^{17}$ Thus, 
Table 3 Extracted assessment or intervention recommendations from eligible CPGs

\begin{tabular}{ll}
\hline $\begin{array}{l}\text { Assessment or } \\
\text { intervention name }\end{array}$ & Recommendation \\
\hline $\begin{array}{l}\text { Screening to detect } \\
\text { amblyopia or risk } \\
\text { factors }\end{array}$ & $\begin{array}{l}\text { The 2017 USPSTF report recommends } \\
\text { vision screening for children aged 3-5 } \\
\text { years of age to detect amblyopia or its risk } \\
\text { factors }\end{array}$ \\
$\begin{array}{l}\text { Examine individuals } \\
\text { with first-degree } \\
\text { relatives with }\end{array}$ & $\begin{array}{l}\text {...first-degree relatives of individuals } \\
\text { diagnosed with glaucoma are considered } \\
\text { glaucoma high risk of developing glaucoma } \\
\text { themselves. It is recommended that they } \\
\text { undergo a full ocular examination by a } \\
\text { qualified healthcare provider, and receive } \\
\text { ongoing monitoring for the development of } \\
\text { glaucoma }\end{array}$
\end{tabular}

\begin{tabular}{|c|c|c|c|}
\hline CPG & SoR & QoE & Remarks on recommendation \\
\hline AAO & Strong & Good & \\
\hline NHMRC & Strong & Good & $\begin{array}{l}\text { The following genetic syndromes } \\
\text { have high associations with } \\
\text { childhood glaucoma: Nail Patella } \\
\text { syndrome with the LMX1B gene, } \\
\text { Axenfeld Rieger syndrome/ } \\
\text { anterior segment dysgenesis } \\
\text { with the PITX2 and FOXC1 genes } \\
\text { and Aniridia with the PAX6 gene. } \\
\text { Patients with these syndromes } \\
\text { or mutations are usually followed } \\
\text { closely for glaucoma. Congenital } \\
\text { glaucoma is associated with } \\
\text { Cyp1B1 mutations in } 17 \% \text { of } \\
\text { Australian families. }\end{array}$ \\
\hline
\end{tabular}

Monitor long-term users of steroids for glaucoma

Comprehensive

eye and vision examination of infants (6-12 months of age) ...long-term users of steroids by any route of administration are at increased risk of glaucoma, and thus require surveillance.

\section{NHMRC Intermediate Moderate There is no evidence from the} secondary literature regarding the risk factors for, or progression of secondary glaucoma.

Infants should receive an in-person AOA Strong Moderate

comprehensive eye and vision assessment

between 6 and 12 months of age for

the prevention and/or early diagnosis and treatment of sight-threatening eye conditions and to evaluate visual development

\begin{tabular}{|c|c|c|c|c|}
\hline $\begin{array}{l}\text { Comprehensive } \\
\text { eye and vision } \\
\text { examination of } \\
\text { children ( } 3-5 \text { years } \\
\text { of age) }\end{array}$ & $\begin{array}{l}\text { Preschool age children should receive } \\
\text { an in-person comprehensive eye and } \\
\text { vision examination at least once between } \\
\text { the ages of } 3 \text { and } 5 \text { years to prevent } \\
\text { and/or diagnose and treat any eye or } \\
\text { vision conditions that may affect visual } \\
\text { development }\end{array}$ & $\mathrm{AOA}$ & Strong & Moderate \\
\hline $\begin{array}{l}\text { Comprehensive } \\
\text { eye and vision } \\
\text { examination before } \\
\text { beginning school }\end{array}$ & $\begin{array}{l}\text { School-age children should receive an } \\
\text { in-person comprehensive eye and vision } \\
\text { examination before beginning school to } \\
\text { diagnose, treat and manage any eye or } \\
\text { vision conditions }\end{array}$ & $\mathrm{AOA}$ & Strong & Moderate \\
\hline $\begin{array}{l}\text { Annual comprehensive } \\
\text { eye and vision } \\
\text { examination of } \\
\text { school-age children }\end{array}$ & $\begin{array}{l}\text { School-age children should receive an } \\
\text { in-person comprehensive eye and vision } \\
\text { examination annually to diagnose, treat and } \\
\text { manage eye or vision problems }\end{array}$ & $\mathrm{AOA}$ & Not stated & $\begin{array}{l}\text { Expert } \\
\text { opinion }\end{array}$ \\
\hline $\begin{array}{l}\text { Assess optic cup:disc } \\
\text { ratio and cup:disc } \\
\text { ratio symmetry }\end{array}$ & $\begin{array}{l}\text { Evidence supports assessment of cup:disc } \\
\text { ratio, and cup:disc ratio asymmetry, } \\
\text { when assessing the risk of glaucomatous } \\
\text { damage occurring... } \\
\text { Evidence supports the value of validated } \\
\text { optic disc comparison techniques } \\
\text { (simultaneous stereo photograph } \\
\text { comparison and confocal scanning laser } \\
\text { tomography) in order to detect longitudinal } \\
\text { changes in the optic nerve }\end{array}$ & NHMRC & Intermediate & Moderate \\
\hline $\begin{array}{l}\text { Gonioscopy of both } \\
\text { eyes }\end{array}$ & $\begin{array}{l}\text {...gonioscopic examination of both eyes } \\
\text { is required when making a diagnosis of } \\
\text { glaucoma }\end{array}$ & NHMRC & Weak & $\begin{array}{l}\text { Expert } \\
\text { opinion }\end{array}$ \\
\hline
\end{tabular}




\begin{tabular}{|c|c|c|c|c|c|}
\hline $\begin{array}{l}\text { Carbonic anhydrase } \\
\text { inhibitors }\end{array}$ & $\begin{array}{l}\text { Evidence indicates caution when using } \\
\text { topical and systemic carbonic anhydrase } \\
\text { inhibitors in children, in situations where } \\
\text { glaucoma is resistant to other treatment } \\
\text { and/or prior to surgery }\end{array}$ & NHMRC & Intermediate & Low & $\begin{array}{l}\text { To limit potential adverse effects, } \\
\text { it is important to adhere to dosage } \\
\text { times, use nasolacrimal system } \\
\text { occlusion (if at all possible in small } \\
\text { children) and use the minimum } \\
\text { dose or limit the number of } \\
\text { medications required. }\end{array}$ \\
\hline Tube surgery & $\begin{array}{l}\text { Evidence strongly supports using } \\
\text { tube surgery for long-term intraocular } \\
\text { pressure control. This is an appropriate } \\
\text { first-choice surgery in patients: } \\
-\quad \text { with eyes at higher risk of failure } \\
\quad \text { from trabeculectomy; } \\
\text { - who have failed trabeculectomy; } \\
-\quad \text { with iridocorneal endothelial } \\
\quad \text { syndrome; } \\
\text { - with various forms of uveitic } \\
\text { (inflammatory) glaucoma. } \\
\text { With aphakic glaucoma. }\end{array}$ & NHMRC & Strong & Moderate & $\begin{array}{l}\text { Tube surgery should be } \\
\text { considered for the primary } \\
\text { procedure in patients in whom } \\
\text { trabeculectomy is likely to fail, } \\
\text { such situations include some } \\
\text { severely traumatised eyes and } \\
\text { secondary paediatric glaucomas. }\end{array}$ \\
\hline
\end{tabular}

AAO, American Academy of Ophthalmology; AOA, American Optometric Association; CPG, clinical practice guideline; NHMRC, National Health and Medical Research Council; QoE, quality of evidence (good, moderate, low expert opinion); SoR, strength of recommendation (strong, intermediate, weak); USPSTF, United States Preventive Services Task Force.

this recommendation could also be based on evidence of the effectiveness of tube surgery in adult populations.

\section{DISCUSSION}

The findings of this systematic review demonstrate that there is a lack of high-quality CPGs aimed at childhood glaucoma. The evidence to formulate recommendations for childhood glaucoma varied substantially, with recommendations related to interventions for the treatment of childhood glaucoma generally of lower-quality evidence compared with recommendations for assessments to detect childhood glaucoma (and other paediatric eye disease). In 2013, The World Glaucoma Association (WGA) formulated consensus guidelines that define childhood glaucoma and bring a more uniform set of terminology to the childhood glaucoma landscape. ${ }^{7}$ While extremely valuable for the field, the WGA consensus document did not pass the PECI inclusion criteria as no formal systematic review was conducted. 
Our review indicates much work still needs to be done to develop strong evidence to inform the development of CPGs.

The number of randomised controlled trials (RCTs) for childhood glaucoma has seen only a marginal increase in the last decade. A recent Cochrane review identified 16 RCTs or quasi-RCTs comparing various surgical interventions for PCG; however, these studies variously compared 9 different surgical interventions and generally had low sample size, making it difficult to draw definite conclusions. ${ }^{20}$ It is also important to address the lack of long-term data on the outcomes of these interventions as childhood glaucoma has potentially lifelong consequences. Measurement of quality of life metrics in future studies with a medium-term to long-term follow-up would be of use.

The results of this review indicate that there is a consensus on the need for children to have an eye examination, conducted by either an eye care professional or as part of a screening programme, to detect paediatric eye diseases. However, these recommendations were not specifically targeted at childhood glaucoma. Limited long-term trends have shown that screening programmes such as the retinopathy of prematurity programme, now mandatory in several countries, may reduce the burden of disease and potential blindness. ${ }^{21}{ }^{22}$ As childhood glaucoma can constitute a multitude of ocular and systemic conditions, early examination of asymptomatic children in the population could potentially increase the chances of early detection and management of these conditions. However, the low incidence of childhood glaucoma means that many children would need to be examined (approximately 20000-33 000) to detect a single case of childhood glaucoma and, from a public health perspective, the costs may not outweigh the benefits. A potential alternative to lower the cost and optimise delivery of these annual screenings would be to combine these visits with vaccination programmes or other currently implemented programmes. ${ }^{23}$ It is also important to consider who will perform childhood eye screening or assessments. The two guidelines on paediatric eye evaluations from the USA recommends that primary care providers perform a basic eye screen of newborns and infants, ${ }^{18}{ }^{24}$ whereas it may be more appropriate for children at high risk of childhood glaucoma to be examined by an ophthalmologist in a secondary or tertiary care setting.

Tube surgery was strongly recommended by the Australian CPG for long-term IOP control of all glaucoma, including some childhood glaucomas. The remaining recommendations for management of childhood glaucoma made in this CPG were of weak or intermediate strength and generally had only low-quality evidence or were based on expert opinion. Furthermore, this Australian CPG was published 10 years ago and, based on the exclusion criteria for this review, is nearly out-of-date. Some recent evidence indicates that the IOP-lowering response to antiglaucoma drugs is often lower in children and thus surgical management is necessary. ${ }^{18}$ It is also important to note that serious side effects can occur in children due to difference in drug pharmacodynamics and pharmacokinetics in children as compared with adults. Use of low-dose preparations, gel-based formulations, punctal occlusion during administration and frequent follow-ups can improve outcomes. ${ }^{25}$ Notable interventions for which formal recommendations (for or against) were not made include trabeculotomy, goniotomy and topical brimonidine eye drops. These interventions were briefly and informally discussed within the Australian guidelines, but as no formal recommendation was made, did not meet the criteria for data extraction. The Australian guideline informally recommended against the use of alpha-2 agonists, such as brimonidine, in children $<7$ years of age due to side effects and informally suggested goniotomy or trabeculotomy as potential interventions for PCG. The absence of a formal recommendation for trabeculotomy or goniotomy may reflect uncertainty in the evidence for these interventions at the time, despite their current widespread use in clinical practice and recommended use for PCG in the WGA consensus guidelines. ${ }^{7}$

Childhood glaucoma is a rare, but devastating, disease. There is generally a lack of high-quality evidence to inform the management of childhood glaucoma and there are few recent, targeted CPGs. CPGs are uniquely situated to be able to combine evidence from a systematic search of the scientific literature and the opinion and experience of experts in the field. The latter is particularly important in childhood glaucoma, where the evidence is relatively sparse. The WGA consensus guidelines were an important step in providing guidance on the best-practice management of childhood glaucoma. However, there is need for a high-quality CPG, incorporating both expert consensus and a systematic search of the literature. Limitations to this study include the inclusion of only CGPs written in English in the last 10 years, which have limited the CGPs identified.

\section{CONCLUSION}

We identified three high-quality CPGs relevant to childhood glaucoma in this systematic review; however, none was specifically targeted at childhood glaucoma. There is a considerable lack of evidence-based guidelines to direct management of childhood glaucoma. A coordinated effort is needed to address this lack of quality data with standardised disease terminology and management strategies to improve outcomes for children with childhood glaucoma.

\section{Author affiliations}

${ }^{1}$ Centre for Eye Research Ireland, Technological University Dublin, Dublin, Ireland ${ }^{2}$ Centre for Ophthalmology and Visual Science, The University of Western Australia, Perth, Western Australia, Australia

${ }^{3}$ Singapore Eye Research Institute, Singapore

${ }^{4}$ Ophthalmic Research Centre, Research Institute for Ophthalmology and Vision Science, Shahid Beheshti University of Medical Sciences, Tehran, Iran

${ }^{5}$ World Health Organization Collaborating Centre for the Eye Care and Prevention of Blindness, Tehran, Iran 
${ }^{6}$ International Centre for Eye Health, London School of Hygiene \& Tropical Medicine, London, UK

${ }^{7}$ Vision and Blindness Prevention Programme, World Health Organization, Geneva, Switzerland

Correction notice This article has been corrected since it first published. Author 'Sare Safi' affiliation has been updated.

Contributors IG conducted the initial literature search. GL and SS conducted title and abstract screening. GL and ST conducted full-text screening, quality appraisal and data extraction. SK and JRE were involved in the conception and design of the study. All authors critically reviewed the manuscript and approved its submission. GL acts as guarantor for the study.

Funding The authors have not declared a specific grant for this research from any funding agency in the public, commercial or not-for-profit sectors.

Competing interests None declared.

Patient consent for publication Not applicable.

Ethics approval This study does not involve human participants.

Provenance and peer review Not commissioned; externally peer reviewed.

Data availability statement Data are available on reasonable request. Templates and data used in this study are available upon reasonable request to the authors.

Supplemental material This content has been supplied by the author(s). It has not been vetted by BMJ Publishing Group Limited (BMJ) and may not have been peer-reviewed. Any opinions or recommendations discussed are solely those of the author(s) and are not endorsed by BMJ. BMJ disclaims all liability and responsibility arising from any reliance placed on the content. Where the content includes any translated material, BMJ does not warrant the accuracy and reliability of the translations (including but not limited to local regulations, clinical guidelines, terminology, drug names and drug dosages), and is not responsible for any error and/or omissions arising from translation and adaptation or otherwise.

Open access This is an open access article distributed in accordance with the Creative Commons Attribution Non Commercial (CC BY-NC 4.0) license, which permits others to distribute, remix, adapt, build upon this work non-commercially, and license their derivative works on different terms, provided the original work is properly cited, appropriate credit is given, any changes made indicated, and the use is non-commercial. See: http://creativecommons.org/licenses/by-nc/4.0/.

ORCID iDs

Gareth Lingham http://orcid.org/0000-0002-8957-0733

Jennifer R Evans http://orcid.org/0000-0002-6137-2030

Stuart Keel http://orcid.org/0000-0001-6756-348X

\section{REFERENCES}

1 Papadopoulos M, Cable N, Rahi J, et al. The British infantile and childhood glaucoma (big) eye study. Invest Ophthalmol Vis Sci 2007;48:4100-6.

2 Aponte EP, Diehl N, Mohney BG. Incidence and clinical characteristics of childhood glaucoma: a population-based study. Arch Ophthalmol 2010;128:478-82.

3 Dandona L, Williams JD, Williams BC, et al. Population-based assessment of childhood blindness in southern India. Arch Ophthalmol 1998;116:545-6.

4 Dorairaj SK, Bandrakalli P, Shetty C, et al. Childhood blindness in a rural population of southern India: prevalence and etiology. Ophthalmic Epidemiol 2008;15:176-82.

5 Elder MJ, De Cock R. Childhood blindness in the West bank and Gaza strip: prevalence, aetiology and hereditary factors. Eye 1993;7(Pt 4):580-3.

6 Kong L, Fry M, Al-Samarraie M, et al. An update on progress and the changing epidemiology of causes of childhood blindness worldwide. J AAPOS 2012;16:501-7.
7 Weinreb RN, Grajewski AL, Papadopoulos M. Childhood glaucoma. The Netherlands: Kugler Publications, 2013.

8 Knight LSW, Ridge B, Staffieri SE, et al. Quality of life in adults with childhood glaucoma: an interview study. Ophthalmol Glaucoma 2021. doi:10.1016/j.ogla.2021.09.007. [Epub ahead of print: 23 Sep 2021].

9 Mandal AK, Gothwal VK, Nutheti R. Surgical outcome of primary developmental glaucoma: a single surgeon's long-term experience from a tertiary eye care centre in India. Eye 2007;21:764-74.

10 Gothwal VK, Seelam B, Mandal AK. Quality of life following surgery for congenital glaucoma: findings of the LVPEI congenital glaucoma registry. Eye 2019;33:659-67.

11 Kantipuly A, Pillai MR, Shroff S, et al. Caregiver burden in primary congenital glaucoma. Am J Ophthalmol 2019;205:106-14.

12 Keel S, Evans JR, Block S, et al. Strengthening the integration of eye care into the health system: methodology for the development of the WHO package of eye care interventions. BMJ Open Ophthalmol 2020;5:e000533.

13 Institute of Medicine Committee on Standards for Developing Trustworthy Clinical Practice Guidelines. Clinical practice quidelines we can trust. Washington DC, USA: National Academies Press, 2011.

14 Wallace BC, Small K, Brodley CE. Deploying an interactive machine learning system in an evidence-based practice center: Abstrackr. Proceedings of the 2nd ACM SIGHIT International Health Informatics Symposium, Miami, Florida, USA: Association for Computing Machinery, 2012:819-24.

15 Brouwers MC, Kho ME, Browman GP, et al. AGREE II: advancing Guideline development, reporting and evaluation in health care. CMAJ 2010;182:E839-42.

16 Rauch A, Negrini S, Cieza A. Toward strengthening rehabilitation in health systems: methods used to develop a WHO package of rehabilitation interventions. Arch Phys Med Rehabil 2019;100:2205-11.

17 National Health and Medical Research Council. Guidelines for the screening, prognosis, diagnosis, management and prevention of glaucoma, 2010.

18 Wallace DK, Morse CL, Melia M, et al. Pediatric eye evaluations preferred practice Pattern®: I. vision screening in the primary care and community setting; II. comprehensive ophthalmic examination. Ophthalmology 2018;125:184-227.

19 AOA Evidence-Based Optometry Guideline Development Group Comprehensive pediatric eye and vision examination. St Louis, MO: American Optometric Association, 2017.

20 Gagrani M, Garg I, Ghate D. Surgical interventions for primary congenital glaucoma. Cochrane Database Syst Rev 2020;8:Cd008213.

21 Seroczyńska M, Grałek M, Kanigowska K. [Analysis of the changes in the causes of blindness and significant vision loss among children and young adults born between 1974 and 2004]. Med Wieku Rozwoj 2007;11:193-216.

22 Reynolds JD, Dobson V, Quinn GE, et al. Evidence-based screening criteria for retinopathy of prematurity: natural history data from the cryo-ROP and light-ROP studies. Arch Ophthalmol 2002;120:1470-6.

23 Honavar SG. Pediatric eye screening - why, when, and how. Indian J Ophthalmol 2018;66:889-92.

24 Donahue S, Nixon C, Section on Opthamology, American Academy of Pediatrics, et al. Visual system assessment in infants, children, and young adults by pediatricians. Pediatrics 2016;137:28-30.

25 Sacchi M, Lizzio RAU, Villani E, et al. Medical management of pediatric glaucoma: lessons learned from randomized clinical trials. Graefes Arch Clin Exp Ophthalmol 2020;258:1579-86.

26 Anwar Z, Wellik SR, Galor A. Glaucoma therapy and ocular surface disease: current literature and recommendations. Curr Opin Ophthalmol 2013;24:136-43.

27 European Glaucoma Society. Terminology and guidelines for glaucoma, 2017.

28 Heijl A, Alm A, Bengtsson B, et al. The glaucoma guidelines of the Swedish Ophthalmological Society. Acta Ophthalmol Suppl 2012;90:1-40. 